\title{
Altered Glut-2 accumulation and $\beta$-cell function in mice lacking the exocrine-specific transcription factor, Mist1
}

\author{
E N Fazio ${ }^{1,2,4}, M$ Everest $^{1,4}$, R Colman $^{2}$, R Wang $^{2-4}$ \\ and $\mathbf{C} \mathbf{L} \mathbf{P i n}^{\mathbf{1}, \mathbf{2}, \mathbf{4}}$
}

Departments of ${ }^{1}$ Paediatrics, ${ }^{2}$ Physiology and Pharmacology and ${ }^{3}$ Medicine, University of Western Ontario, Canada

${ }^{4}$ Children's Health Research Institute, London, Ontario, Canada

(Requests for offprints should be addressed to C Pin, Department of Paediatrics, University of Western Ontario, Children's Health Research Institute, London, Ontario N6C 2V5, Canada; Email: cpin@uwo.ca)

\begin{abstract}
Mist1 is an exocrine-specific transcription factor that is necessary for the establishment of cell organization and function of pancreatic acinar cells. While Mist1 is not expressed in the endocrine pancreas, the disorganized phenotype of the exocrine component may affect endocrine function. Therefore, we examined endocrine tissue morphology and function in Mist1-knockout $\left(\right.$ Mist $\left.1^{K O}\right)$ mice. Endocrine function was evaluated using a glucose-tolerance test on 2-10-month-old female mice and revealed a significant reduction in glucoseclearing ability in 10-month-old Mist $1^{K O}$ mice compared with wild-type mice. Immunohistochemical analysis of islet hormone expression indicated that the decreased
\end{abstract}

endocrine function was not due to a decrease in insulin-, glucagon- or somatostatin-expressing cells. However, a decrease in the size of islets in 10 -month-old Mist $1^{\text {KO }}$ mice was observed along with a decrease in Glut-2 protein accumulation. These results suggest that the islets in Mist $1^{K O}$ mice are functionally compromised, likely accounting for the decreased glucose tolerance. Based on these findings, we have identified that the loss of a regulatory gene in the exocrine compartment can affect the endocrine component, providing a possible link between susceptibility for various pancreatic diseases.

Journal of Endocrinology (2005) 187, 407-418

\section{Introduction}

The pancreas originates from the foregut endoderm at approximately embryonic day (E) 8.5 when signals from the mesoderm commit cells to a pancreatic fate (Gittes \& Rutter 1992). By approximately E13.5, the division of pancreatic precursor cells into either acinar, islet or duct cells is apparent morphologically (Slack 1995). The differentiation of these cells is regulated by the correct temporal and spatial expression of a series of transcription factors that direct pancreatic commitment to either an exocrine or endocrine fate (reviewed by Edlund 2001). The earliest expressed transcription factor that is necessary for both pancreatic cell lineage commitment and islet cell differentiation is pancreas duodenum homeobox 1 ( $\mathrm{Pdx} 1$; Jonsson et al. 1994). Pdx1 plays an essential role in pancreatic branching, differentiation and maintenance of insulin-secreting $\beta$-cells (Offield et al. 1996, Holland et al. 2002). Other key transcription factors that are integral to pancreatic development include pancreas transcription factor 1, p48 subunit (PTF1-p48, PTF1a; Krapp et al. 1996) and neurogenin 3 (Gradwohl et al. 2000), which contribute to exocrine- and endocrine-specific differentiation, respectively (Kim \& MacDonald 2002).

Although the endocrine and exocrine components are delineated early in development and they are morphologically and functionally distinct, their coexistence involves complex paracrine interactions that affect pancreatic cell function and disease. For example, insulin potentiates acetylcholine-induced amylase release in rat pancreatic acini, possibly due to an effect on intracellular free calcium levels in pancreatic exocrine cells (Singh \& Adeghate 1998). Cholecystokinin octapeptide (CCK-8) can help to regenerate exocrine tissue in cases of pancreatitis, but insulin is required for this regeneration as diabetic rats do not possess CCK-8-mediated regenerative ability. In these diabetic rats, administration of exogenous insulin restores regenerative ability (Hegyi et al. 2004). Alternatively, the development of pancreatitis, which results in the destruction of the exocrine parenchyma and increased inflammation, contributes to eventual destruction of the endocrine parenchyma (Sarles et al. 1990). This destruction leads to endocrine insufficiency in $60 \%$ of pancreatitis patients (Dimagno \& Dimagno 2004). Even improper 
development in one compartment can affect the outcome of the other compartment, as observed following deletion of either exocrine (PTF1a) or endocrine (BETA2)-specific transcription factors (Krapp et al. 1998, Naya et al. 1997).

Recently we have been characterizing a mouse model of exocrine pancreatic disease. These mice carry a genespecific deletion for Mist1, an exocrine-specific transcription factor belonging to the basic helix-loop-helix family of proteins (Lemercier et al. 1997). Mist1 is initially expressed in the pancreas beginning at approximately E10.5 and persists to high levels in the adult pancreas (Pin et al. 2000). Characterization of Mist1 expression in adult tissues reveals a restricted pattern exclusive to cells with an exocrine function. Mist1-knockout (Mist $1^{\text {KO }}$ ) animals exhibit defective acinar cell organization and impaired function, and by 12 months of age, they develop pancreatic lesions similar to those found in chronic pancreatitis (Pin et al. 2001). At the functional level, Mist ${ }^{K O}$ mice exhibit deficits in cell communication (Rukstalis et al. 2003), acinar cell development (Johnson et al. 2004), calcium homeostasis and regulated exocytosis (Luo et al. 2005).

Due to the defects in exocrine cell function and morphology, we hypothesize that the alteration in exocrine pancreas function of Mist $1^{K O}$ mice leads to altered function of the endocrine pancreas. To examine this, functional and morphological analysis of endocrine tissue was conducted in young ( 2 months), adult ( $3-5$ months) and old (10 months) Mist $1^{K O}$ mice. We observed that 10-month-old Mist $1^{K O}$ mice were intolerant to highglucose challenge with a significantly smaller islet size, suggesting that exposure to chronic exocrine pancreas deficiency causes an adverse affect on the endocrine component of the pancreas. Interestingly, immunofluorescence (IF) and Western-blot analysis for a $\beta$-cell-specific glucose transporter 2 (Glut-2; Guillam et al. 1997) indicates a significant loss of this protein as early as 2 months. This result suggests that the islets in Mist $1^{K O}$ mice are functionally compromised, which may, over time, contribute to functional endocrine defects.

\section{Materials and Methods}

Mice

All mice in this study were derived from matings between C57/BL6 mice and SvJ129 mice. Progeny carried a single gene replacement of the Mist1 coding region with the bacterial lac $Z$ gene (Pin et al. 2001). Heterozygous mice for the Mist1 allele (Mist $\left.1^{\text {LacZ }}\right)$ were back-crossed to C57/BL6 mice for at least seven generations producing an average C57/BL6 background purity of $99.6 \%$. The resulting matings generated the wild-type (WT) and Mist $1^{K O}$ (both Mist 1 alleles replaced) mice used in these studies. All experiments using mice were approved by the animal care committee at the University of Western
Ontario and mice were handled according to regulations stipulated by the Canadian Council on Animal Care.

\section{Glucose-tolerance and plasma insulin ELISA analysis}

Female mice (2-10 months old) were fasted overnight and blood glucose levels were measured prior to intraperitoneal administration of $2 \mathrm{~g} / \mathrm{kg}$ D-glucose $(t=0)$. Following injection, blood glucose levels were monitored at $t=10$, 20, 40, 60, 90 and 120 min post-injection using tail blood with a Fast-Take Glucosemeter (Lifescan, Burnaby, British Columbia, Canada). Area under the curve (AUC) represents absolute glucose tolerance and was calculated for the glucose-tolerance profile of each mouse using the trapezoidal method (Allison et al. 1995). Pancreata were dissected and immediately processed for immunohistochemistry and protein extraction.

To measure plasma insulin levels, mice were killed 5, 20 or $120 \mathrm{~min}$ after glucose administration and blood obtained through cardiac puncture. Serum insulin was determined from 10-month-old WT and Mist $1^{K O}$ mice as per the manufacturer's protocol using a Mercodia Ultrasensitive $(0-6 \cdot 5 \mu \mathrm{g} / \mathrm{l})$ mouse insulin ELISA kit (ALPCO Diagnostics, Windham, New Hampshire, USA). At this time, pancreatic tissue was dissected and weighed. Relative pancreatic size was determined as a percentage of total mouse body weight. To determine the overall amount of endocrine tissue within the pancreas, the weight of the pancreas was multiplied by the percentage of endocrine tissue determined by microscopic morphometric analysis (see below).

\section{Immunofluorescence for pancreatic proteins}

For developmental analysis, whole embryos were obtained from timed matings based on the presence of a vaginal plug (marked as E0.5). For adult studies, pancreata were dissected from WT and Mist $1^{K O}$ female mice and embedded in Cryomatrix (Fisher) as previously described (Pin \& Merrifield 1997). Using a Shandon cryostat, tissues were cut into $6 \mu \mathrm{m}$ sections, mounted onto slides (Fisher) and stored at $-20{ }^{\circ} \mathrm{C}$ until use. Sections were first fixed with $4 \%$ formaldehyde, and permeabilized with $0.1 \%$ Triton X-100 for $10 \mathrm{~min}$. Sections were blocked (5\% BSA in $0 \cdot 1 \%$ Triton $\mathrm{X}-100)$ then incubated for $1 \mathrm{~h}$ with primary antibodies, including rabbit anti-amylase $(1: 1000$; Calbiochem), mouse anti-insulin (1:500; Sigma), rabbit anti-glucagon (1:100; Sigma), rabbit anti-pdx1 (1:1000; a generous gift from Dr C. Wright, Vanderbilt University, Nashville, Tennessee, USA), rabbit anti-Glut-2 (1:500; Chemicon), rabbit anti-somatostatin (1:50; Chemicon) and rabbit anti-Mist1 (1:1000; Pin et al. 2001). In some cases, dual labeling was performed by co-incubating insulin-specific antibodies with glucagon-, Glut-2-, somatostatin- or pdx1-specific antibodies. Tissue was washed three times in PBS and incubated in secondary 
antibodies (1:100 of goat anti-mouse tetramethylrhodamine $\beta$-isothiocyanate (TRITC) or goat anti-rabbit fluorescein isothiocyanate (FITC; Sigma). For double labeling, secondary antibodies were combined in a single incubation. Tissue was washed three times in PBS followed by a 5-min incubation in DAPI (1:1000), and slides mounted with Vectashield (Vector Laboratories, Burlingame, CA, USA). Cell counting for insulin, glucagon and Glut-2 was performed by counting the cells of 10 islets for WT $(n=4)$ and Mist ${ }^{K O}(n=4)$ sections.

\section{BrdU staining}

Paraffin sections of mouse pancreata were cleared with two 5-min treatments with toluol followed by a graded series of ethanol washes. A methanol/ $\mathrm{H}_{2} \mathrm{O}_{2}$ mixture was used to clear sections of any peroxidase activity and then sections were rinsed with distilled water. Two 3-min PBS washes were followed by incubation with a protease solution $(0.05 \%$ protease in $0.5 \mathrm{M}$ Tris buffer at $\mathrm{pH} 7.5$ or $0 \cdot 1 \%$ trypsin in PBS, $\mathrm{pH} 7 \cdot 8)$ for $5 \mathrm{~min}$ at $37^{\circ} \mathrm{C}$. To stop the protease reaction distilled water was added, followed by two 3 -min washes with PBS. A $30-\min 37^{\circ} \mathrm{C}$ incubation in $2 \mathrm{M} \mathrm{HCl}$ was followed by two 5 -min washes in borate buffer $\left(0 \cdot 1 \mathrm{M} \mathrm{Na}_{2} \mathrm{~B}_{4} \mathrm{O}_{7}, \mathrm{pH} 8 \cdot 5\right)$. Tissue sections were then washed in $1 \times$ PBS and incubated with a mouse monoclonal anti-BrdU (Sigma) antibody overnight at $4{ }^{\circ} \mathrm{C}$. Slides were washed in PBS and then incubated with goat anti-mouse Ig/Biotin (Jackson Laboratories) for $30 \mathrm{~min}$ at room temperature. Sections were washed with PBS and incubated in streptavidin ABC/horseradish peroxidase solution (Dako) for $30 \mathrm{~min}$. This step was followed by washing the slides and developing the sections with diaminobenzidine $(7 \mathrm{mM}$ diaminobenzidine and $0 \cdot 3 \% \mathrm{H}_{2} \mathrm{O}_{2}$ in PBS) for $5 \mathrm{~min}$. $\mathrm{CuSO}_{4}$ was used for another $5 \mathrm{~min}$ and then slides were washed in running tap water for $5 \mathrm{~min}$ to stop enzyme activity.

\section{Islet analysis}

Cryostat sections were stained with either hematoxylin and eosin or dual IF for insulin/glucagon. Quantitative evaluation was performed using computer-assisted image analysis with OpenLab 4.0 Modular Software for Scientific Imaging (Improvision). Under low magnification $(50 \times)$ the area of the pancreas was manually traced using Openlab software, excluding large blood vessels and connective tissue accumulations. At higher magnification $(400 \times)$, individual islets were identified by insulin/glucagon staining, and manually traced. In total, nine random sections were chosen and the islets counted and measured. For each animal, at least 19 islets were assessed with a median of 32 islets measured. Analysis parameters included total number of islets per unit area of pancreas, total percentage of endocrine tissue area per whole pancreas area, and number of insulin- and glucagon-expressing cells per islet.

\section{Western blotting and densitometry}

Tissue-protein extraction, protein electrophoresis and immunoblotting were performed as described previously (Johnson et al. 2004). For immunoblot analysis, $40 \mu \mathrm{g}$ of WT and Mist $1^{K O}$ pancreatic protein was loaded onto a 12\% SDS/PAGE gel. Proteins were transferred to a PVDF membrane by semi-dry transfer, and probed with rabbit anti-Glut-2 (1:2500 in 5\% non-fat dried milk; Chemicon) for $1 \mathrm{~h}$. Blots were rinsed three times in PBS and incubated with anti-rabbit horseradish peroxidaseconjugated secondary antibody (1:2000 in 5\% non-fat dried milk, Sigma). Following a second series of washes, the membrane was incubated with LumiGlo chemiluminescent substrate (Mandel Marketplace), exposed to film (Kodak) and developed. Densitometry was performed on Western-blot autoradiographs for 2- $(n=4)$ and 10-month $(n=6) \mathrm{WT}$ and Mist $1^{\text {KO }}$ protein samples. Autoradiographs were analysed using a Fluorochem 8800 documentation system and accompanying Fluorochem 8800 software (Alpha Inotech, San Leandro, CA, USA).

\section{Statistical analyses}

Data are expressed as means \pm S.E.M All statistical analyses were performed using Graphpad Prism 4.02 for Windows (GraphPad Software, San Diego, CA, USA). For comparison between two groups, the paired Mann-Whitney $U$ test was used, where significance was obtained if $P<0 \cdot 05$. Glucose-tolerance time courses were statistically analysed using two-way repeated-measures analysis of variance (ANOVA) and a Bonferroni post-hoc test.

\section{Results}

Glucose tolerance and insulin secretion in $W T$ and Mist $1^{\mathrm{KO}}$ mice

Our previous analysis of Mist1 expression in the adult pancreas indicated specific expression limited to acinar cells (Pin et al. 2000). To confirm this restriction in expression during pancreatic development, pancreatic sections were obtained from E16.5 WT mice and analyzed for Mist1, amylase and insulin expression using IF (Fig. 1). As expected, Mist1 expression was localized to the nuclei of cells outside of the developing endocrine compartment (Fig. 1A). This expression corresponds directly with exocrine tissue based on amylase expression (Fig. 1C), whereas Mist1 and insulin were not co-expressed (Fig. 1D and $\mathrm{E})$.

The altered exocrine morphology and increased exocrine tissue damage that occurs in the absence of Mist1 (Pin et al. 2001) suggests that a possible defect in endocrine function may exist. To address this possibility, a glucosetolerance test was performed on 2-, 4- and 10-month-old $\mathrm{WT}$ and Mist $1^{\mathrm{KO}}$ animals (Fig. 2). Fasting blood glucose 

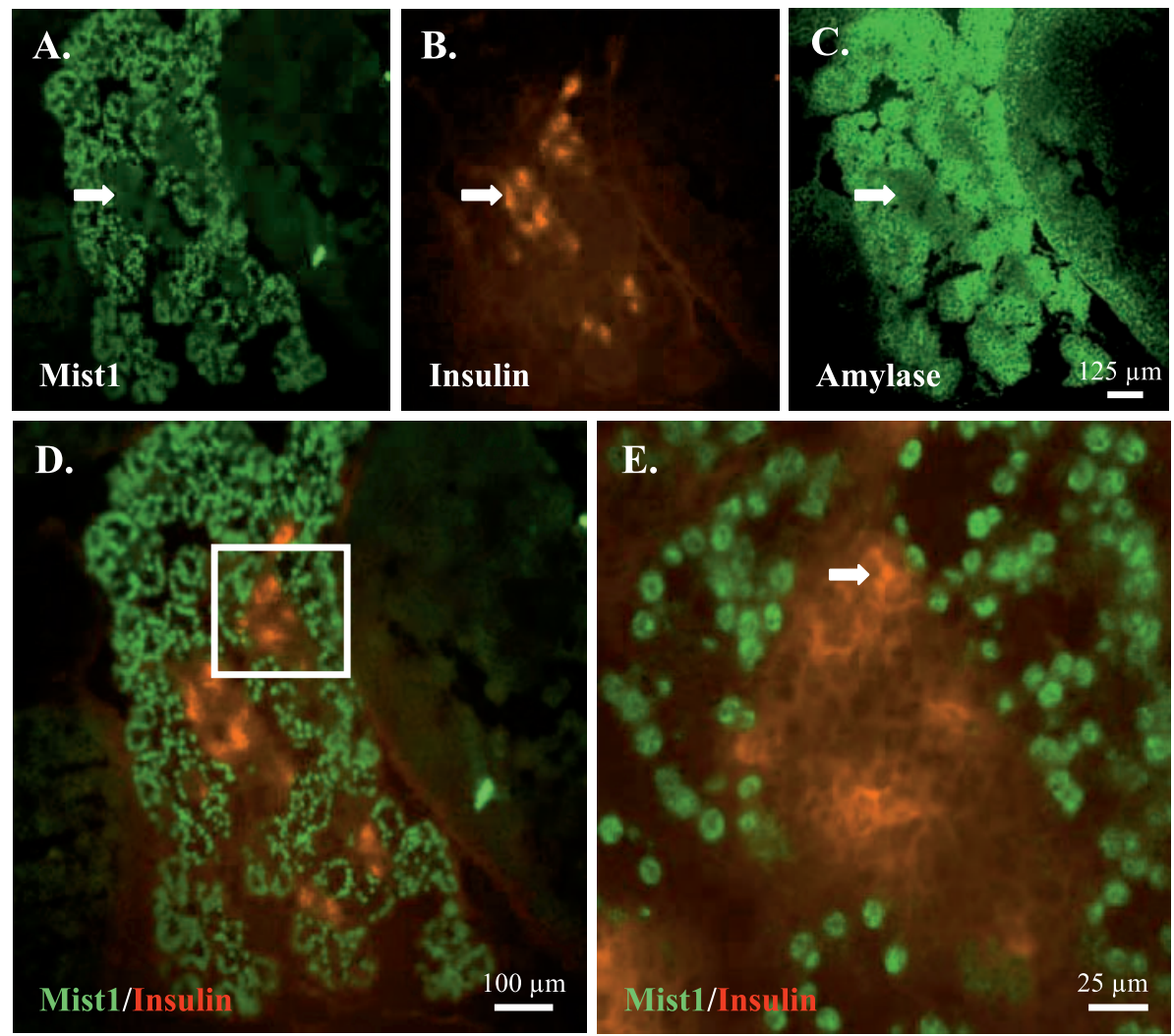

Figure 1 Mist1 is expressed only in the exocrine compartment of the developing pancreas. IF analysis of E16.5 pancreatic tissue reveals Mist1 expression (A) limited to nuclei of cells in regions that are negative for insulin (B) and positive for amylase (C). By combining the staining for insulin (red) and Mist1 (green), the developing islets are seen to be Mist1-negative (D). (E) Higher magnification of the boxed area from (D) confirms this exclusivity of Mist1 and insulin staining (arrow). The scale bar on (C) applies to (A)-(C).

levels in 2-month-old animals were not significantly different between WT and Mist $1^{K O}$ mice $(n=7$; Fig. 2A, $t=0)$. After glucose challenge, a peak blood glucose level was reached 10 min post-glucose stimulation in both WT and Mist ${ }^{\text {KO }}$ groups $(14.9 \pm 1.38$ and $15 \cdot 1 \pm 0.95 \mathrm{mmol} / \mathrm{l}$, respectively). There was no significant difference in blood glucose levels between the groups at any time point following administration of glucose, indicating a similar ability to respond to increased glucose concentration in 2-month-old WT and Mist $1^{K O}$ animals. This was confirmed by measuring the AUC for the glucose-tolerance time course (Fig. 2B), which indicated equivalent glucose-clearing capacity.

Since there is a progressive increase in the severity of the exocrine phenotype of Mist $1^{K O}$ mice with age (Pin et al. 2001), glucose tolerance was assessed in 4- and 10-monthold animals. No significant difference was observed in 4-month-old animals (Fig. 2C and D), either in fasting glucose levels or following glucose injection, as illustrated by the similar profiles of the glucose-tolerance curves for WT and Mist $1^{K O}$ mice ( $n=6$; Fig. 2C). Fasting blood glucose levels in 10-month-old mice revealed no difference between WT and Mist $1^{K O}$ animals (Fig. 2E, $t=0$ ). Following glucose injection, peak blood glucose levels were obtained within 10-20 min for both groups. At 10 min post-glucose stimulation, blood glucose levels were significantly higher $(P<0 \cdot 05)$ in Mist $1^{K O}$ animals $(15 \cdot 9 \pm$ $1.0 \mathrm{mmol} / \mathrm{l})$ compared with WT mice $(12.9 \pm 1.2 \mathrm{mmol} / \mathrm{l})$. This difference remained at $20 \mathrm{~min}$, where the average blood glucose level in WT mice $(13.2 \pm 1.4 \mathrm{mmol} / \mathrm{l})$ was significantly lower $(P<0 \cdot 03)$ than Mist ${ }^{K O}$ levels $(19 \cdot 4 \pm$ $1.5 \mathrm{mmol} / \mathrm{l})$. The higher blood glucose levels in Mist $1^{\mathrm{KO}}$ mice persisted at 40 min post-stimulation when Mist $1^{K O}$ glucose levels reached $16 \cdot 0 \pm 1.0 \mathrm{mmol} / \mathrm{l}$ in contrast to $11 \cdot 3 \pm 1 \cdot 1 \mathrm{mmol} / 1$ attained by WT mice. By $60 \mathrm{~min}$, WT and Mist $1^{K O}$ animals displayed similar blood glucose levels. AUC determination confirmed that absolute blood glucose tolerance in Mist $1^{K O}$ mice was significantly less than that of WT mice, indicating a decreased glucoseclearing capacity in Mist $1^{K O}$ animals $(P<0 \cdot 005$; Fig. $2 \mathrm{~F})$.

A delayed response in glucose clearance from blood could suggests deficits in insulin secretion. Therefore, the 
A.
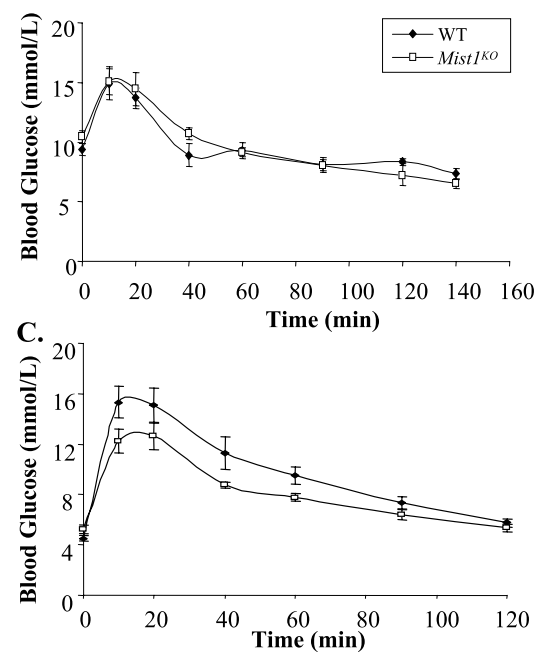

E.
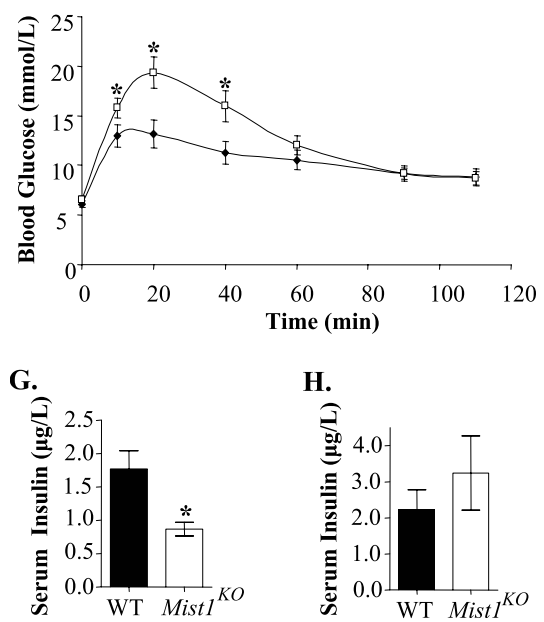

B.

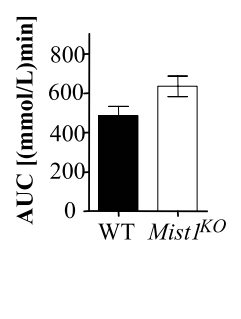

D.

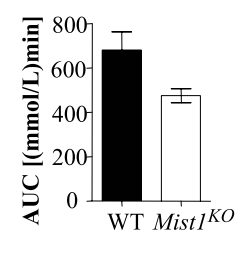

F.

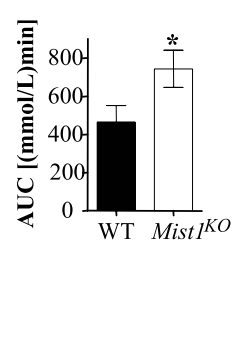

I.

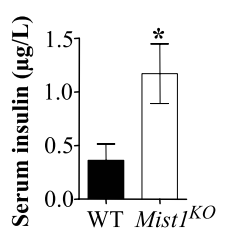

Figure 2 Mist $^{K O}$ mice exhibit decreased glucose tolerance at 10 months. In $2(\mathrm{~A} ; n=7)$ and $4(\mathrm{C} ; n=6)$-month-old animals, no differences in the blood glucose levels were observed between WT $(\checkmark)$ and Mist $1^{K O}(\square)$ animals at any time point after glucose injection. However, 10-month-old Mist ${ }^{K O}$ mice (E) exhibited significantly higher blood glucose levels when compared with WT counterparts at $t=10,20$ and 40 min $\left({ }^{*}, P<0.05\right)$ after administration of glucose. By $t=60$ min both WT $(n=16)$ and Mist $1^{K O}(n=22)$ mice exhibited similar blood glucose levels. Analysis of the AUC corroborates a decreased tolerance $\left({ }^{*}, P<0.05\right)$ only in 10-month-old Mist ${ }^{K O}$ mice (F) with no difference at 2 (B) and 4 months (D) from WT littermates. Plasma insulin levels were analyzed in 10-month-old animals at 5 (G), 20 $(\mathrm{H})$ and 120 (I) min post-glucose exposure. At $5 \mathrm{~min}$, there was significantly less serum insulin in Mist $1^{K O}$ mice compared with WT mice $\left({ }^{*}, P<0 \cdot 05\right)$. By 20 min post-glucose exposure, Mist $1^{K O}$ mice exhibited a trend toward higher serum insulin levels than WT counterparts that reaches significance at the experimental endpoint of $120 \mathrm{~min}\left({ }^{*}, P<0 \cdot 05\right)$. All results are shown \pm S.E.M.

plasma insulin levels were assessed at 5,20 and $120 \mathrm{~min}$ following glucose stimulation in 10-month-old mice. At 5 min post-glucose administration there was a significant

$(P<0 \cdot 05)$ difference observed between WT and Mist $1^{\text {KO }}$ animals (Fig. 2G). WT mice exhibited insulin levels that were approximately double that observed in Mist $1^{\text {KO }}$ animals $(1 \cdot 92 \pm 0 \cdot 28(n=5)$ versus $0 \cdot 87 \pm 0 \cdot 1 \mu \mathrm{g} / 1(n=6))$. At $20 \mathrm{~min}$ post-stimulation (Fig. $2 \mathrm{H}$ ), Mist $1^{\mathrm{KO}}$ mice exhibited higher serum insulin levels than their WT counterparts $(3.24 \pm 1.03$ and $2.23 \pm 0.55 \mu \mathrm{g} / 1$ respectively; $n=5$ ) that was not statistically different. At the experimental endpoint of $120 \mathrm{~min}$ post-glucose exposure (Fig. 2I), Mist $1^{K O}$ mice serum insulin levels $(1 \cdot 17 \pm$ $0.23 \mu \mathrm{g} / 1 ; n=8)$ were significantly higher $(P<0.03)$ than the levels observed in WT animals $(0.36 \pm 0.15 \mu \mathrm{g} / \mathrm{l}$; $n=7)$.

\section{Islet morphology in WT and Mist ${ }^{\mathrm{KO}}$ pancreas}

Due to a change in the ability of Mist $1^{K O}$ mice to efficiently reduce blood glucose levels, general islet morphology was compared between WT and Mist ${ }^{K O}$ mice in 2- and 10-month-old mice (Fig. 3, Table 1). At 2 months, there was no significant difference in islet density between WT $\left(1.6 \pm 0.37\right.$ islets $\left./ \mathrm{mm}^{2} ; n=6\right)$ and Mist $1^{K O}$ mice $\left(1.59 \pm 0.30\right.$ islets $/ \mathrm{mm}^{2} ; n=5$; Fig. 3A). However, at 10 months of age Mist $1^{K O}$ mice exhibited a significantly higher islet density when compared with WT mice $\left(0.82 \pm 0.08\right.$ versus $0.49 \pm 0.07$ islets $/ \mathrm{mm}^{2} ; n=13 ; P<0 \cdot 05$; Fig. 3B). Analysis of islet size in 10-month-old mice indicated that the average islet size in WT mice was greater than that in Mist $1^{\text {KO }}$ tissue $(12950 \pm 1557$ versus $9827 \pm 1002 \mu \mathrm{m}$; Fig. 3C). This difference was not statistically significant, which is likely due to the large variability in islet size found in Mist $1^{K O}$ pancreatic tissue (Fig. 3D-F). Comparison of total endocrine area revealed a modest increase in the overall amount of endocrine tissue within the pancreata of 10 -month-old Mist $1^{\text {KO }}$ mice with no significant difference observed (Table 1). To determine whether the increase in islet density is due to more islets in Mist $1^{K O}$ mice, the wet weight of the pancreas was compared between WT and Mist $1^{\mathrm{KO}}$ mice. At 2 months of age, there is no difference in relative pancreatic weight (Fig. $3 \mathrm{G}$ ). At 10 months of age there is a significant decrease in the relative pancreatic weight of Mist $1^{K O}$ mice $(0 \cdot 37 \pm 0 \cdot 02 \% ; n=17)$ compared with WT mice $(0.54 \pm 0.03 \% ; n=15$; Fig. $3 \mathrm{H})$. This difference results in a $31.4 \%$ decrease in pancreatic size for Mist $1^{K O}$ mice. By including the percentage of endocrine tissue within the pancreata of WT and Mist $1^{K O}$ mice $(0.67$ versus $0 \cdot 77 \%$ ), this suggests an overall reduction of $21 \cdot 1 \%$ in the endocrine component of Mist $1^{K O}$ pancreatic tissue.

The expression of $\mathrm{pdx} 1$ and various endocrine hormones was then compared between WT and Mist $1^{\text {KO }}$ mice using IF analysis (Fig. 4). No obvious alterations were observed in the expression of pdx1 (Fig. 4B and E), as in all cases its expression was limited to the nuclei of insulin-positive $\beta$-cells (Fig. 4C and F). Similarly, there was no alteration in the expression of insulin (Fig. 4A, D, 
A. Two month

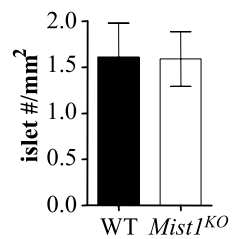

B. Ten month

C.
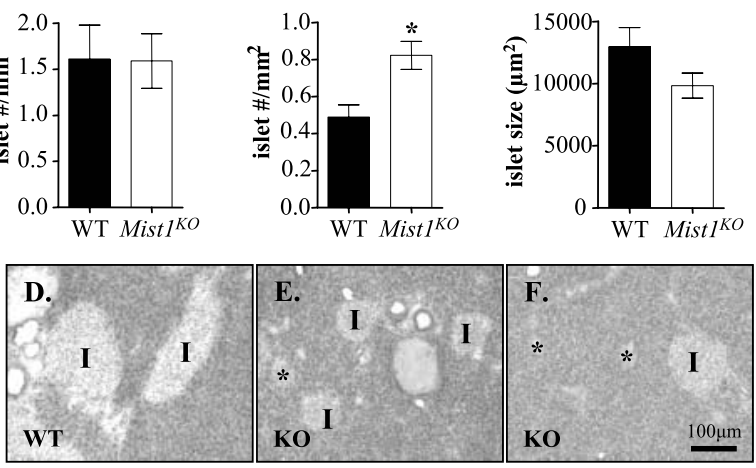

G.

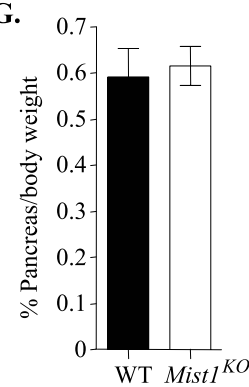

H.

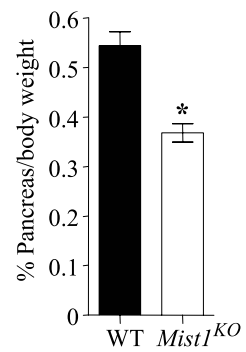

Figure 3 Morphometric analysis reveals alterations in the endocrine pancreas of Mist $1^{\mathrm{KO}}$ animals. (A) Examination of islet number $/ \mathrm{mm}^{2}$ in 2-month-old animals showed no significant difference between WT and Mist $1^{K O}$ animals $(n=5)$. (B) 10-month-old Mist $1^{K O}$ mice exhibit a significantly higher number of islets per unit area than their WT counterparts $\left({ }^{*}, P<0.05\right.$; $n=12$ ). (C-F) However, a decrease in islet size was observed in hematoxylin- and eosin-stained sections of pancreatic tissue from 10-month-old Mist $1^{K O}$ animals (E, F) compared with WT mice (D); see also (C). I, islets; *, small islets. These observations are supported by measuring islet area using OpenLab 4.0 software, and suggest a decreased average islet size in Mist ${ }^{K O}$ pancreatic tissue compared with WT islets at 10 months of age $(n=12)$. $(\mathrm{G}, \mathrm{H})$ Analysis of relative pancreatic weight between WT and Mist $1^{K O}$ mice show no difference at 2 months of age $(G ; n=5)$, but there is a significant difference in the relative pancreatic weights at 10 months with Mist $1^{K O}$ pancreata at only $68 \%$ the size of WT tissues $\left(\mathrm{H} ; n=15\right.$ for WT and 17 for Mist $\left.1^{K O} ;{ }^{*}, P<0 \cdot 05\right)$. All results are shown \pm S.E.M.
$\mathrm{G}$ and $\mathrm{J}$ ) or glucagon (Fig. $4 \mathrm{H}$ and $\mathrm{K}$ ) observed in Mist $1^{\mathrm{KO}}$ mice, indicating that the dysfunction in glucose tolerance of the Mist $1^{K O}$ mice is not due to an absence of $\beta$-cells or altered cellular distribution within the islets. To confirm this finding, the percentage of $\beta$ - and $\alpha$-cells within the islets was calculated and revealed no difference in their cellular contribution to islets of WT and Mist $1^{\mathrm{KO}}$ mice. For WT mice, $73.04 \pm 3 \cdot 26 \%$ of the islet cells expressed insulin and $16.76 \pm 1.5 \%$ expressed glucagon, while Mist $1^{K O}$ islets contained $71 \cdot 75 \pm 1 \cdot 63$ and $20 \cdot 13 \pm 0 \cdot 65 \%$ of insulin and glucagon cells, respectively (Fig. 4M). Additionally, there was no observable difference in the localization of $\delta$-cells between WT and Mist $1^{K O}$ islets (data not shown). The change in the size of islets within Mist $1^{K O}$ pancreata could suggest differential turnover of $\beta$-cells within the tissue. Therefore, we injected Mist $1^{\text {KO }}$ and WT mice with BrdU and assessed the percentage of proliferating cells within the pancreatic islet tissue, using immunohistochemical analysis for BrdU incorporation (Fig. 4N, Table 1). In WT mice $2 \cdot 5 \pm 0 \cdot 6 \%$ of all islet cells were BrdU-positive and in Mist $1^{K O}$ mice $2 \cdot 1 \pm 0 \cdot 4 \%$ of all islet cells were BrdU-positive, suggesting no significant change in the islet cell-turnover rate.

\section{Glut-2 analysis}

The decreased ability to clear glucose, coupled with the smaller islet size suggests that the islets in Mist $1^{\mathrm{KO}}$ mice are functionally compromised. Therefore, the expression of Glut-2 was examined in both WT and Mist $1^{K O}$ animals to assess one functional component of glucose sensing in $\beta$-cells. IF for Glut-2 revealed expression in 2-month-old WT (Fig. 5B) and Mist ${ }^{K O}$ (Fig. 5E) islets. In 10-monthold mice, Glut-2 protein was readily observed in WT mice (Fig. $5 \mathrm{H}$ ) but was difficult to observe in $\beta$-cells of Mist $1^{K O}$ islets (Fig. 5K). While lower magnifications make it hard to visualize Glut-2 expression in Mist ${ }^{K O}$ islets, at higher magnifications trace amounts of Glut-2 expression were observed (Fig. 5N). To confirm this decrease in Glut-2 accumulation, Western-blot analysis was performed on

Table 1 Morphometric comparison of pancreatic tissue from 10-month-old WT and Mist $1^{K O}$ mice

Body weight (g)

Pancreatic weight $(\mathrm{mg})$

Pancreatic weight as percentage of body weight

Amount of endocrine tissue area (\%)

Endocrine tissue $(\mathrm{mg}) \dagger$

Islet density (islets $/ \mathrm{mm}^{2}$ )

Average islet size $\left(\mu \mathrm{m}^{2}\right)$

Proliferating islet cell (\%)

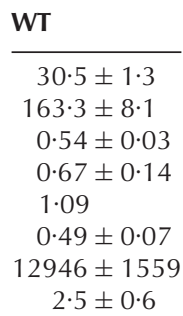

*Determined to be a significant difference $(P<0 \cdot 05)$.

†Determined by multiplying the percentage area of endocrine tissue by pancreatic weight. 

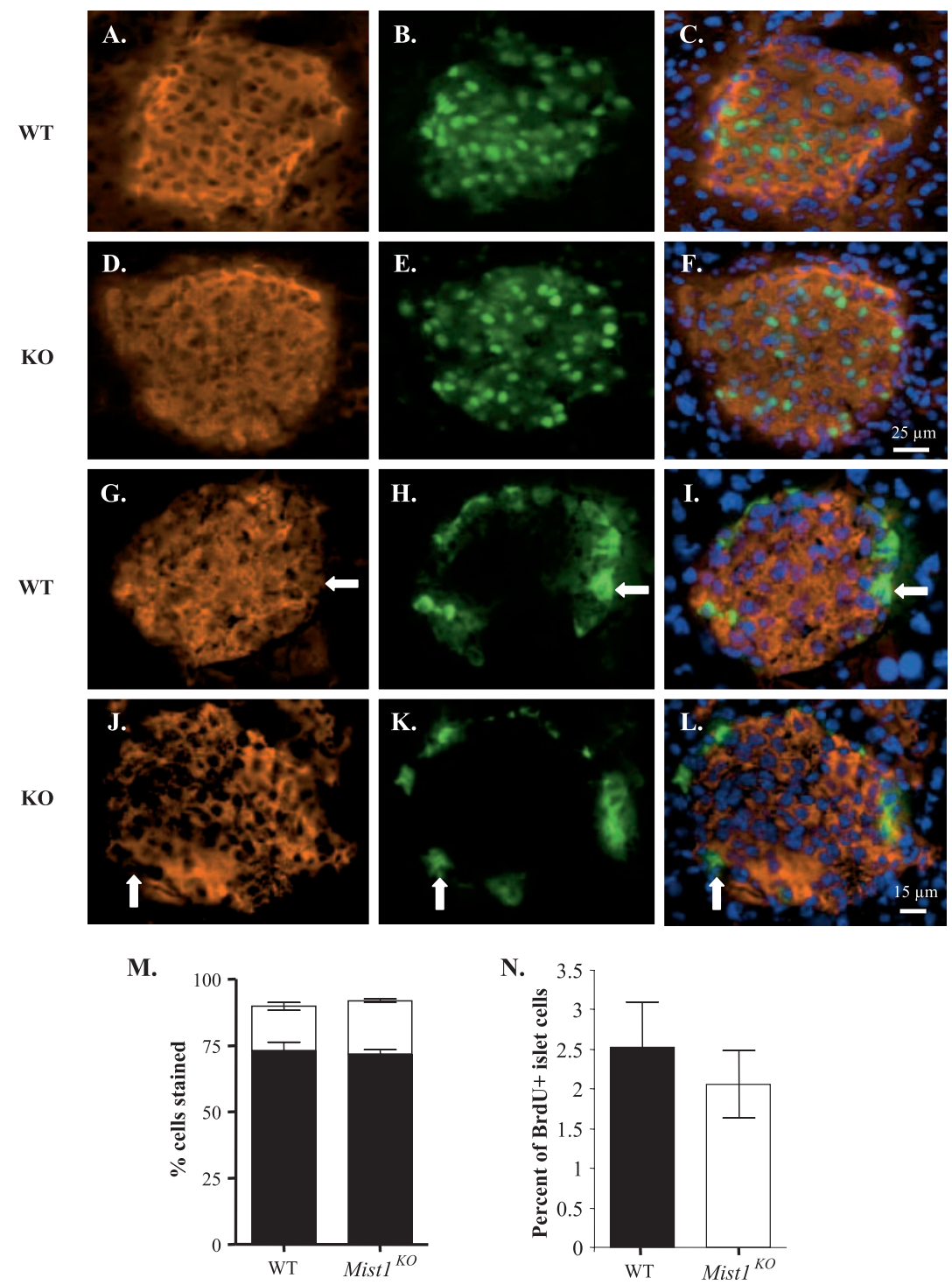

Figure 4 The expression of $p d x 1$ and the proportion of $\alpha$ - and $\beta$-cells were unaltered in Mist $1^{K O}$ islets. Co-localization of insulin (A, D) with $p d x 1(B, E)$ reveals no significant difference in the localization of $\mathrm{pdx} 1$ between WT $(\mathrm{A}-\mathrm{C})$ and Mist $1^{\mathrm{KO}}(\mathrm{D}-\mathrm{F})$ animals. $\mathrm{Pdx} 1$ expression is restricted in both WT $(\mathrm{C})$ and $\operatorname{Mist}^{\mathrm{KO}}(\mathrm{F})$ tissue to the $\beta$-cell compartment as shown in merged images. Analysis for insulin $(\mathrm{G}, \mathrm{J})$ and glucagon $(\mathrm{H}, \mathrm{K})$ reveals no spatial differences in the location of these endocrine cell types between WT $(\mathrm{G}-\mathrm{I})$ and Mist $^{\mathrm{KO}}$ mice (J-L). In addition, co-localization of insulin and glucagon expression is not observed in Mist $7^{K O}$ islets (I, L; arrows). Nuclei are stained with DAPI. (M) Quantification of the percentage of $\alpha$ - and $\beta$-cells in the WT and Mist $1^{K O}$ islets reveals equivalent amounts of insulin- and glucagon-positive cells (black, insulin; white, glucagon). (N) Analysis of pancreatic tissue following BrdU injections reveals no differences in the percentage of islet cells undergoing proliferation in Mist $1^{K O}$ tissue. All results are shown \pm S.E.M.; $n=4$.

pancreatic extracts from WT and Mist $1^{K O}$ mice. In 10-month-old Mist $1^{K O}$ mice Glut-2 expression was virtually undetectable, supporting the IF results (Fig. 6A). Densitometric analysis on four independent protein samples indicated Glut-2 protein levels in Mist $1^{\text {KO }}$ pancreatic tissue to be only $13 \%$ of the WT levels (Fig. 6B). Surprisingly, analysis of whole pancreatic protein extracts from 2-month-old mice also revealed a significant decrease in Glut-2 protein level in Mist $1^{K O}$ mice to $19 \%$ of the amount observed in WT samples, 

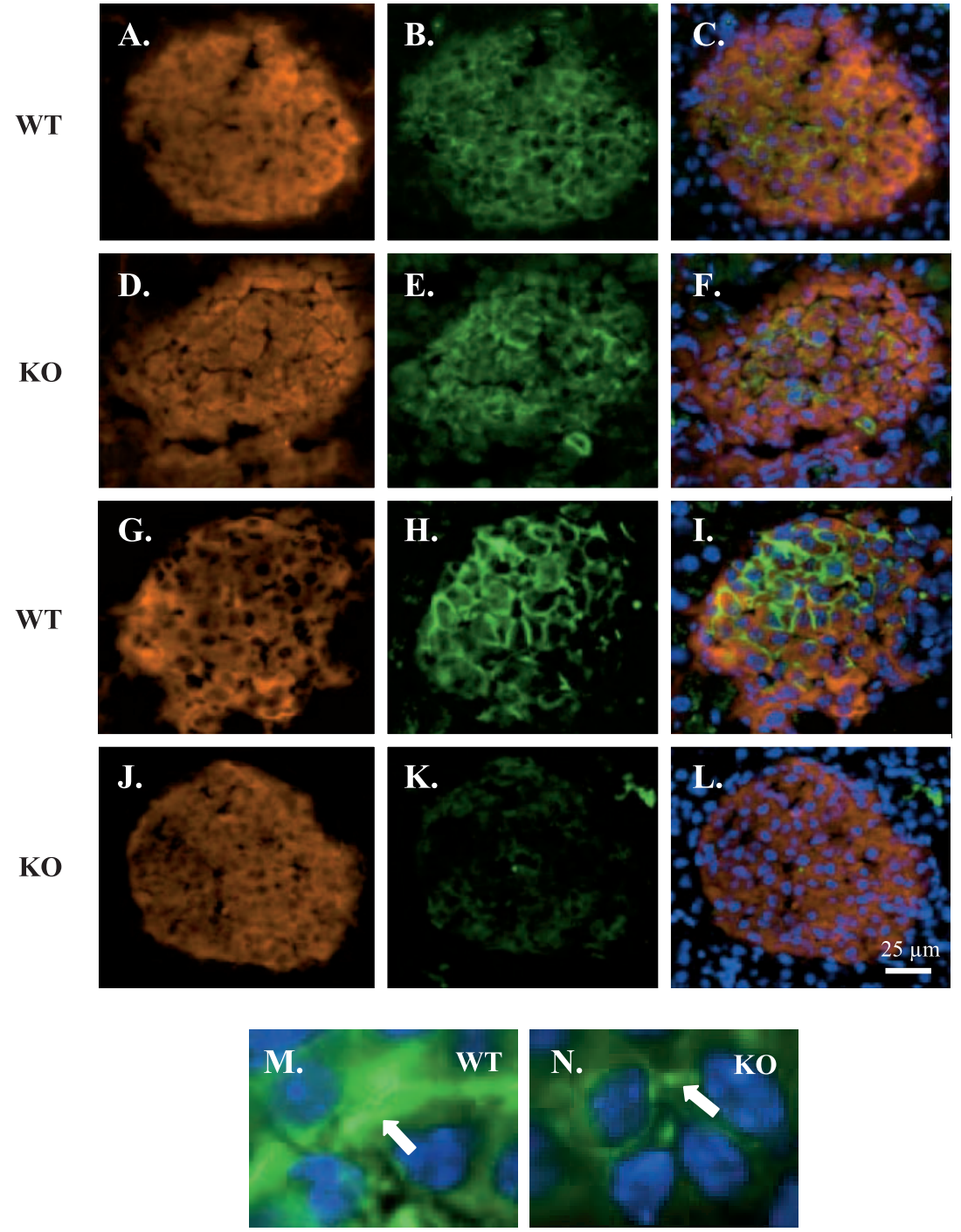

Figure $5 \mathrm{IF}$ reveals a decrease in Glut-2 expression in Mist ${ }^{K O}$ animals. At 2 months of age Glut-2 expression is observed in both WT (B) and Mist $1^{K O}$ islets (E) specifically localized to insulin-expressing cells ( $A$ and $D$, respectively). At 10 months of age, WT animals maintain Glut-2 expression to high levels $(\mathrm{H})$, still limited to insulin-expressing cells (G). However, Mist ${ }^{K O}$ islets exhibited limited to no Glut-2 expression (K) in insulin-positive cells $(\mathrm{J})$. Fluorescent channels have been combined to highlight co-expression $(\mathrm{C}, \mathrm{F}, \mathrm{I}, \mathrm{L})$. (M, N) High-magnification images of WT $(\mathrm{M})$ and Mist ${ }^{K O}(\mathrm{~N})$ pancreatic tissue reveals trace amounts of Glut-2 expression in most islet cells (arrows).

a result that was not observed by the IF analysis (Fig. 6C and D). The difference between IF and Western-blot analysis highlights the inability to correctly quantify protein expression levels by IF. To confirm that gender is not a determinant in the differential expression of Glut-2 in WT and Mist $1^{K O}$ mice, Western-blot analysis was performed on 2-month male protein samples (WT and Mist $\left.1^{K O}, n=4\right)$. Analysis showed that there is a decrease in Glut-2 levels in 2-month-old Mist $1^{\mathrm{KO}}$ mice similar to that found in female 2-month-old Mist ${ }^{\mathrm{KO}}$ mice (Fig. 6E), ruling out any gender exclusivity. These results indicate that the effects on islet protein expression precede the functional deficit observed in the Mist $1^{K O}$ mice.

To understand whether the deficiency in Glut-2 expression is due to a decrease in the number of Glut-2expressing cells, a decrease in Glut-2 expression within in each cell, or a combination of both, we manually counted the percentage of Glut-2-positive cells within the islets of WT and Mist $1^{K O}$ pancreatic tissue (Fig. 6F). Cell counting followed by a paired Mann-Whitney $U$ test illustrated 
A.
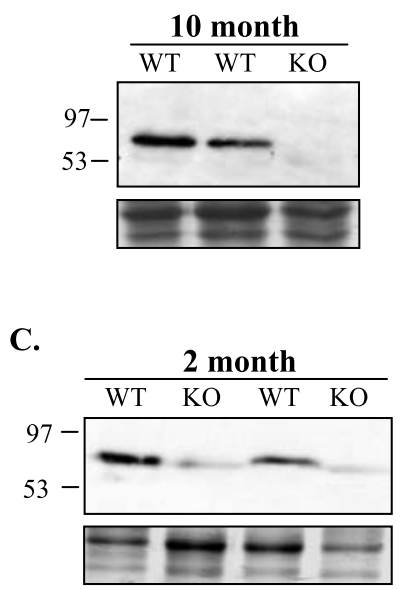

E.

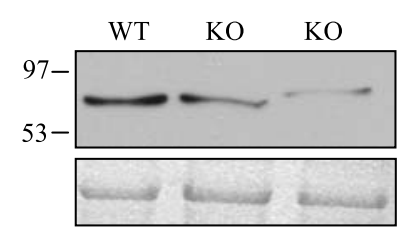

B.

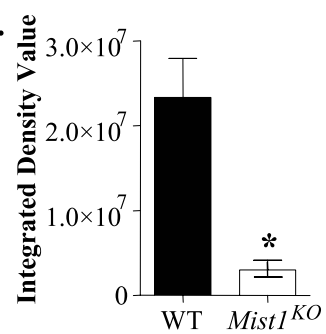

D.

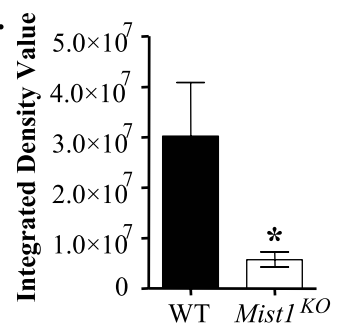

F.

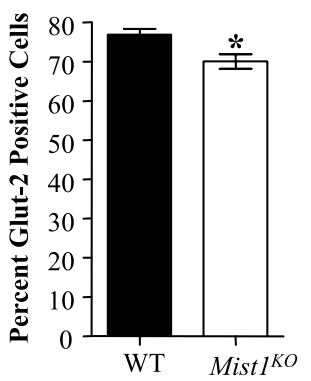

G.

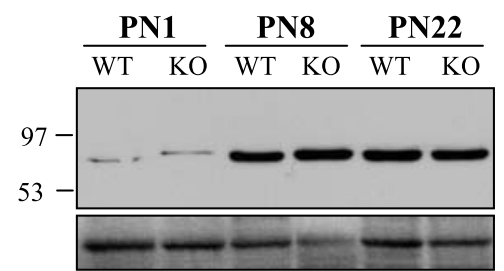

Figure 6 The decrease in Glut-2 expression predates endocrine deficiency in Mist $1^{K O}$ mice. Western-blot analysis indicates that at both 10 (A) and 2 months (C) Glut-2 expression is readily observed in all WT samples with faint or no Glut-2 expression in Mist $1^{K O}$ pancreatic extracts. Protein loading was evaluated through Coomassie Brilliant Blue staining of equivalently loaded gels. Individual band densitometry reveals a significant decrease in band intensity in $10-(B)$ and 2 -month Mist $1^{K O}$ mice $(D ; P<0 \cdot 01)$.

(E) Western-blot analysis with male 2-month pancreatic protein samples shows that the decrease in Glut-2 expression was not limited to female mice. (F) Individual cell counts highlight that there was a significant decrease $\left({ }^{*} P<0 \cdot 05\right)$ in the number of islet cells that express Glut-2 in 10-month Mist $1^{K O}$ mice. (G)

Western-blot analysis of pancreatic extracts from WT and Mist ${ }^{K O}$ mice reveals no difference in expression of Glut-2 at postnatal (PN) days 1, 8 and 22. Results are shown \pm S.E.M.; $n=4(10$ months $)$ or $n=6$ (2 months).

that there is a significant decrease in the percentage of Glut-2-positive cells in Mist $1^{K O}$ islets versus WT islets,

with $70 \cdot 0 \pm 1 \cdot 8$ and $76 \cdot 8 \pm 1 \cdot 5 \%$ of cells staining, respectively $(P<0 \cdot 05)$. However, this difference does not account for the $80-90 \%$ reduction in Glut-2 expression in Mist $1^{\text {KO }}$ tissue. Therefore, while there may be a decrease in the number of Glut-2-positive cells in Mist $1^{K O}$ pancreata, it appears that Mist $1^{K O} \beta$-cells accumulate Glut-2 to lower levels than WT $\beta$-cells.

Finally, to determine whether the loss of Glut-2 was a primary defect in Mist $1^{K O}$ pancreatic tissue, the expression of Glut-2 was compared between WT and Mist $1^{\mathrm{KO}}$ tissue through postnatal development. Protein extracts were obtained from tissue at postnatal days 1, 8 and 22 and compared by Western-blot analysis. At these postnatal time points, equivalent amounts of Glut- 2 protein are consistently observed. Since alterations in exocrine cell organization (Johnson et al. 2004) and gene expression (Rukstalis et al. 2003) are observed at birth in Mist $1^{\text {KO }}$ mice, the loss of Glut-2 expression is a secondary defect in Mist $1^{K O}$ mice.

\section{Discussion}

In this study, we have identified deficiencies in the endocrine pancreas that are brought on by deletion of the exocrine-specific transcription factor, Mist1. Older Mist $1^{K O}$ mice exhibit deficits in pancreatic and islet size, glucose tolerance and insulin secretion. IF analysis suggests that the islets in Mist $1^{K O}$ mice are functionally compromised due to a significant reduction in the expression of the glucose transporter, Glut-2, in adult $\beta$-cells. Importantly, while the functional defects in insulin response may not be apparent in younger Mist $1^{K O}$ animals, the islets within these animals exhibit changes in Glut-2 protein expression that occur after weaning but prior to 2 months of age. The timing of decreased Glut-2 expression suggests that this is a secondary defect in the Mist $1^{K O}$ phenotype, occurring after the cellular disorganization observed in acinar cells. These results implicate exocrine pancreas dysfunction as a factor for defects in endocrine tissue morphology and function.

The decreased endocrine function observed in 10month-old Mist $1^{K O}$ mice was illustrated by the comparison of both glucose tolerance and insulin secretion to WT mice. Significantly higher levels of plasma glucose were observed following intraperitoneal (IP) injections, possibly reflecting defects in glucose sensing leading to a delayed release of insulin. The first phase of glucose simulated insulin secretion (GSIS) normally proceeds with a peak serum insulin levels occurring 5 min post-glucose stimulation (Curry et al. 1968). Peak levels are reached this quickly since the $\beta$-cell's first response is to release all stored insulin to combat elevated blood glucose levels (Wollheim et al. 1980, Del Prato et al. 2002). The second phase of GSIS follows at approximately $20 \mathrm{~min}$ postglucose exposure and can persist until blood glucose levels 
are normalized (Grodsky \& Bolaffi 1992). Peak serum insulin levels in phase 2, however, do not reach those attained in phase 1 since this phase relies on the inherent ability of the $\beta$-cell to produce insulin, not release stored quantities (Wollheim et al. 1980). We observed drastically decreased serum insulin levels in 10 -month Mist ${ }^{K O}$ mice compared with WT counterparts $5 \mathrm{~min}$ post-glucose exposure, which suggests a general delay in the onset of insulin release. At $20 \mathrm{~min}$ post-glucose stimulation, Mist $1^{K O}$ mice have recovered to attain serum levels equivalent to WT levels. It is at approximately this time point where insulin secretion is able to commence through the delayed sensing of glucose. By $120 \mathrm{~min}$ post-glucose stimulation, the average plasma insulin level in Mist $1^{K O}$ mice was significantly higher than that of WT mice, even though the blood glucose level at this time point is similar to that of WT animals. While perfusion experiments would be ideal to fully assess alterations in GSIS in these mice, this time-point analysis suggests that the phase 1 GSIS in 10 -month-old Mist $1^{K O}$ mice is compromised and that their ability to store or release stored insulin is altered. The observed increase in plasma insulin at 120 min may be compensatory for a deficiency in early insulin release.

Deficits in glucose tolerance and insulin secretion could be due to a decrease in islet mass relative to total body weight. The pancreatic weight for Mist $1^{K O}$ mice is $68 \%$ of that seen in their WT counterparts, a difference that was seen for both female (Fig. 3) and male (data not shown) mice, indicating that this alteration is not gender specific. Taking into consideration the increase in endocrine tissue per pancreatic area, this translates into a $20 \%$ decrease in overall islet mass. However, studies involving partial pacreatectomy suggest that even a $60 \%$ loss of islet mass does not cause glucose intolerance (Anneren 2002), making it unlikely that the modest decrease in islet mass is the cause of endocrine defects in Mist $1^{K O}$ mice. We would suggest that the decrease in Glut-2 expression is the underlying cause for the decreased glucose tolerance in 10 month Mist $1^{K O}$ mice. Glut-2 is a glucose-sensing and -transporting molecule located on the surface of $\beta$-cells. Homozygous deletion of Glut-2 (solute carrier family 2 member $2, \operatorname{sic} 2 a 2)$ results in alterations in the postnatal development of pancreatic islets and increases susceptibility to hyperglycemia, relative hypoinsulinemia, abnormal glucose tolerance and decreased glucose-stimulated insulin gene expression. Interestingly, Glut-2-null mice exhibit a loss of first-phase GSIS, but the second phase of GSIS remains unaffected (Guillam et al. 1997). These observations are all consistent with the phenotypes observed in Mist $1^{K O}$ mice, suggesting that alterations in $\beta$-cells may be the result of a loss of Glut- 2 expression and not the reverse scenario. In addition, the absence of Glut-2 has been observed in different animal models of diabetes (Jorns et al. 1996, Bonny et al. 1997). It is unclear why the decrease in Glut-2 expression at 2 months does not alter glucose clearance. One possible explanation is that a threshold level of Glut-2 is required for proper glucose tolerance. At 2 months this threshold may still be exceeded, whereas by 10 months Glut- 2 levels may fall below the required threshold resulting in aberrant $\beta$-cell function and altered glucose tolerance. In support of this theory, Glut-2 heterozygous mice, which only have a single copy of the Glut-2 gene, exhibit no alterations in glucose tolerance (Guillam et al. 1997).

The loss of Glut-2 expression in Mist $1^{K O} \beta$-cells over time suggests intriguing cross-talk between exocrine and endocrine compartments in which the deletion of an exocrine-specific transcription factor results in the decreased expression of an endocrine-specific protein. While we cannot absolutely exclude the possibility that Mist1 is expressed at very low levels in $\beta$-cells, all previous work on Mist1 has indicated that the protein is limited to the exocrine compartment of the pancreas (Pin et al. 2000, 2001, Rukstalis et al. 2003, Zhu et al. 2004), which we have confirmed here during development. Therefore, Mist1 would not be able to directly affect transcription of the Glut-2 gene. Western-blot analysis revealed a decrease in Glut-2 protein by 2 months in Mist $1^{K O}$ mice, suggesting that the loss of Glut-2 is not a primary defect in Mist $1^{K O}$ mice, but likely a secondary effect. The fact that a change in Glut-2 expression was not observed by IF analysis in 2-month-old mice is likely due to the fact that IF reflects only qualitative aspects of protein expression, such as localization, and is not an accurate reflection of protein levels. The progressive loss of Glut-2 protein could reflect changes in the endocrine cell compartment due to long-term exposure to the altered exocrine compartment of Mist $1^{K O}$ mice. Alternatively, $\beta$-cell renewal may be compromised with replacement cells not able to reach full functional maturity. Based on previous reports, $98 \%$ of the $\beta$-cells would be replaced within the time frame of this experiment (i.e. 10 months; Dor et al. 2004). If a deficiency in Glut-2 staining was the result of replacement $\beta$-cells not expressing Glut-2, one would expect patchy islet expression with some cells expressing normal Glut-2 levels and other cells expressing little to no Glut-2 expression. Given the uniform level of staining observed for Glut-2 in both young and older Mist $1^{K O}$ mice, we believe that the decreases represent a general decrease in Glut-2 accumulation in all islet cells.

Altered regulation of Glut-2 expression in Mist $1^{\mathrm{KO}}$ mice can occur at different molecular levels, including that of gene transcription, mRNA translation, and protein stability or degradation. Although the transcriptional regulation of Glut-2 is not yet fully understood, it is known that $\mathrm{Pdx} 1$ transcriptionally activates the gene encoding Glut-2 (Wang et al. 2001). To date we have been unable to detect a change in the expression of Pdx-1 mRNA (A S Kowalik and C L Pin, unpublished observations) and protein between $\mathrm{WT}$ and Mist $1^{K O}$ mice. Alternatively, other signaling factors activated in Mist $1^{K O}$ 
pancreatic tissue may directly or indirectly regulate Glut-2 protein accumulation. We have previously identified increased expression of Reg1 in Mist $1^{K O}$ mice (Pin et al. 2001), a factor involved in islet regeneration and $\beta$-cell proliferation (Akiyama et al. 2001, Unno et al. 2002). Whether Reg1 is protective of the islets in a damaging exocrine environment or reflective of islet damage is unclear. However, there is no increase in the proliferation rate of islet cells in the absence of Mist1 expression in 10-month-old mice. In addition, we have identified extensive tissue remodeling based on matrix metalloproteinase (MMP) activation in Mist $1^{K O}$ pancreatic tissue (data not shown). Increased MMP activity has been linked to increased islet neogenesis in $P d x 1 / P b \times 1$ double heterozygous mice which develop age-dependent overt diabetes mellitus (Kim et al. 2002). The increase in MMP activity may also be reflective of the general deterioration of the exocrine compartment in 10-month-old Mist ${ }^{K O}$ mice.

In conclusion, we have now identified specific biochemical and functional alterations that occur in endocrine pancreatic tissue following deletion of an exocrine-specific transcription factor. This study implies that a complex paracrine environment exists between the tissues that are necessary for functional maturation. Disruptions in this environment would have implications on the function and susceptibility for disease for both the exocrine and endocrine pancreas.

\section{Funding}

This work was supported by grants to CP (MOP 53083) CP/RW (MB06B4) and RW (MOP-53227) from the Canadian Institutes of Health Research and Children's Health Research Institute. The authors declare that there is no conflict of interest that would prejudice the impartiality of this scientific work.

\section{References}

Akiyama T, Takasawa S, Nata K, Kobayashi S, Abe M, Shervani NJ, Ikeda T, Nakagawa K, Unno M, Matsuno S \& Okamoto H 2001 Activation of Reg gene, a gene for insulin-producing beta -cell regeneration: poly(ADP-ribose) polymerase binds Reg promoter and regulates the transcription by autopoly(ADP-ribosyl)ation. PNAS 98 48-53.

Allison DB, Paultre F, Maggio C, Mezzitis N \& Pi-Sunyer FX 1995 The use of areas under curves in diabetes research. Diabetes Care 18 245-250.

Anneren C 2002 Dual role of the tyrosine kinase GTK and the adaptor protein SHB in beta-cell growth: enhanced beta-cell replication after $60 \%$ pancreatectomy and increased sensitivity to streptozotocin. Journal of Endocrinology 172 145-153.

Bonny C, Roduit R, Gremlich S, Nicod P, Thorens B \& Waeber G 1997 The loss of GLUT2 expression in the pancreatic beta-cells of diabetic $\mathrm{db} / \mathrm{db}$ mice is associated with an impaired DNA-binding activity of islet-specific trans-acting factors. Molecular \& Cellular Endocrinology 135 59-65.
Curry DL, Bennett LL \& Grodsky GM 1968 Dynamics of insulin secretion by the perfused rat pancreas. Endocrinology 83 572-584.

Del Prato S, Marchetti P \& Bonadonna RC 2002 Phasic insulin release and metabolic regulation in type 2 diabetes. Diabetes $\mathbf{5 1}$ Suppl 1 S109-S116.

Dimagno MJ \& Dimagno EP 2004 Chronic pancreatitis. Current Opinion in Gastroenterology 20 444-451.

Dor Y, Brown J, Martinez OI \& Melton DA 2004 Adult pancreatic beta-cells are formed by self-duplication rather than stem-cell differentiation. Nature 429 41-46.

Edlund H 2001 Developmental biology of the pancreas. Diabetes 50 Suppl 1 S5-S9.

Gittes GK \& Rutter WJ 1992 Onset of cell-specific gene expression in the developing mouse pancreas. PNAS 89 1128-1132.

Gradwohl G, Dierich A, LeMeur M \& Guillemot F 2000 neurogenin3 is required for the development of the four endocrine cell lineages of the pancreas. PNAS 97 1607-1611.

Grodsky GM \& Bolaffi JL 1992 Desensitization of the insulin-secreting beta cell. Journal of Cell Biochemistry 48 3-11.

Guillam MT, Hummler E, Schaerer E, Yeh JI, Birnbaum MJ, Beermann F, Schmidt A, Deriaz N \& Thorens B 1997 Early diabetes and abnormal postnatal pancreatic islet development in mice lacking Glut-2. Nature Genetics 17 327-330.

Hegyi P, Rakonczay-Jr Z, Sari R, Czako L, Farkas N, Gog C, Nemeth J, Lonovics J \& Takacs T 2004 Insulin is necessary for the hypertrophic effect of cholecystokinin-octapeptide following acute necrotizing experimental pancreatitis. World Journal of Gastroenterology 10 2275-2277.

Holland AM, Hale MA, Kagami H, Hammer RE \& MacDonald RJ 2002 Experimental control of pancreatic development and maintenance. PNAS 99 12236-12241.

Johnson CL, Kowalik AS, Rajakumar N \& Pin CL 2004 Mist1 is necessary for the establishment of granule organization in serous exocrine cells of the gastrointestinal tract. Mechanisms of Development 121 261-272.

Jonsson J, Carlsson L, Edlund T \& Edlund H 1994 Insulin-promoterfactor 1 is required for pancreas development in mice. Nature 371 606-609.

Jorns A, Tiedge M, Sickel E \& Lenzen S 1996 Loss of GLUT2 glucose transporter expression in pancreatic beta cells from diabetic Chinese hamsters. Virchows Archiv 428 177-185.

Kim SK \& MacDonald RJ 2002 Signaling and transcriptional control of pancreatic organogenesis. Current Opinion in Genetic Development 12 540-547.

Kim SK, Selleri L, Lee JS, Zhang AY, Gu X, Jacobs Y \& Cleary ML $2002 \mathrm{Pbx} 1$ inactivation disrupts pancreas development and in Ipf1deficient mice promotes diabetes mellitus. Nature Genetics 30 430-435.

Krapp A, Knofler M, Frutiger S, Hughes GJ, Hagenbuchle O \& Wellauer PK 1996 The p48 DNA-binding subunit of transcription factor PTF1 is a new exocrine pancreas-specific basic helix-loophelix protein. EMBO Journal 15 4317-4329.

Krapp A, Knofler M, Ledermann B, Burki K, Berney C, Zoerkler N, Hagenbuchle O \& Wellauer PK 1998 The bHLH protein PTF1-p48 is essential for the formation of the exocrine and the correct spatial organization of the endocrine pancreas. Genes $\mathcal{E}$ Development 12 3752-3763.

Lemercier C, To RQ, Swanson BJ, Lyons GE \& Konieczny SF 1997 Mist1: a novel basic helix-loop-helix transcription factor exhibits a developmentally regulated expression pattern. Developmental Biology 182 101-113.

Luo X, Shin DM, Wang X, Konieczny SF \& Muallem S 2005 Aberrant localization of intracellular organelles, $\mathrm{Ca} 2+$ signaling and exocytosis in Mist1 null mice. Journal of Biological Chemistry 280 26922-26927.

Naya FJ, Huang HP, Qiu Y, Mutoh H, DeMayo FJ, Leiter AB \& Tsai MJ 1997 Diabetes, defective pancreatic morphogenesis, and abnormal enteroendocrine differentiation in BETA2/neuroDdeficient mice. Genes \& Development 11 2323-2334. 
Offield MF, Jetton TL, Labosky PA, Ray M, Stein RW, Magnuson MA, Hogan BL \& Wright CV 1996 PDX-1 is required for pancreatic outgrowth and differentiation of the rostral duodenum. Development 122 983-995.

Pin CL \& Merrifield PA 1997 Developmental potential of rat L6 myoblasts in vivo following injection into regenerating muscles. Developmental Biology 188 147-166.

Pin CL, Bonvissuto AC \& Konieczny SF 2000 Mist1 expression is a common link among serous exocrine cells exhibiting regulated exocytosis. Anatomical Records 259 157-167.

Pin CL, Rukstalis JM, Johnson C \& Konieczny SF 2001 The bHLH transcription factor Mist1 is required to maintain exocrine pancreas cell organization and acinar cell identity. Journal of Cell Biology 155 519-530.

Rukstalis JM, Kowalik A, Zhu L, Lidington D, Pin CL \& Konieczny SF 2003 Exocrine specific expression of Connexin32 is dependent on the basic helix-loop-helix transcription factor Mist1. Journal of Cell Science 116 3315-3325.

Sarles H, Bernard JP \& Gullo L 1990 Pathogenesis of chronic pancreatitis. Gut 31 629-632.

Singh J \& Adeghate E 1998 Effects of islet hormones on nervemediated and acetylcholine-evoked secretory responses in the isolated pancreas of normal and diabetic rats. International Journal of Molecular Medicine 1 627-634.

Slack JM 1995 Developmental biology of the pancreas. Development 121 1569-1580.

Unno M, Nata K, Noguchi N, Narushima Y, Akiyama T, Ikeda T, Nakagawa K, Takasawa S \& Okamoto H 2002 Production and characterization of Reg knockout mice: reduced proliferation of pancreatic beta-cells in Reg knockout mice. Diabetes $\mathbf{5 1}$ Suppl 3 S478-S483.

Wang H, Maechler P, Ritz-Laser B, Hagenfeldt KA, Ishihara H, Philippe J \& Wollheim CB 2001 Pdx1 level defines pancreatic gene expression pattern and cell lineage differentiation. Journal of Biological Chemistry 276 25279-25286.

Wollheim CB, Siegel EG, Kikuchi M, Renold AE \& Sharp GW 1980 The role of extracellular $\mathrm{Ca}^{2+}$ and islet calcium stores in the regulation of biphasic insulin release. Hormones \& Metabolic Research Suppl Suppl 10 108-115.

Zhu L, Tran T, Rukstalis JM, Sun P, Damsz B \& Konieczny SF 2004 Inhibition of Mist1 homodimer formation induces pancreatic acinar-to-ductal metaplasia. Molecular Cell Biology 24 2673-2681.

Received 14 September 2005

Accepted 22 September 2005 